\title{
Introduction to the Handbook of Salutogenesis
}

\author{
Maurice B. Mittelmark
}

\section{Introduction}

"A handbook is sometimes referred to as a vade mecum (Latin, "go with me") or pocket reference that is intended to be carried at all times. It may also be referred to as an enchiridion." Ah, the wonders of Wikipedia, which goes on to say that handbooks are "compendiums of information in a particular field or about a particular technique" (http://en. wikipedia.org/wiki/Handbook). This handbook, in either its online open access form or its printed form, is obviously not suited to the pocket. Nor does it aspire to be anything more or less than the first compendium of information about the topic "salutogenesis," in English at any rate.

The need for a handbook of salutogenesis has long been felt by researchers in the field. When an eager colleague first enters the salutogenesis research arena, there has been no easy introduction to the topic. The out-of-print "must read" texts by Aaron Antonovsky $(1979,1987)$ have not been easy to obtain. Antonovsky's brief but vital 1996 paper in Health Promotion International challenges health promotion to adopt salutogenesis as a theory for the field (Antonovsky, 1996). What has happened with salutogenesis in the two decades since 1996? Lindström and Eriksson's (2010) The Hitchhiker's Guide to Salutogenesis: Salutogenic Pathways to Health Promotion is an excellent introductory guide, but not a compendium of handbook dimensions. The same team of Lindström and Eriksson has produced a fine series of journal articles on various aspects of salutogenesis (Eriksson \& Lindström, 2005, 2006, 2007, 2008; Lindström \& Eriksson, 2005, 2006, 2010). Of course, their articles are cited repeatedly throughout this Handbook, testimony to their importance (and readers are urged to visit the website of the Center on Salutogenesis at University West, Sweden,

M.B. Mittelmark $(\bowtie)$

Department of Health Promotion and Development, Faculty of Psychology, University of Bergen, Bergen, Norway e-mail: maurice.mittelmark@uib.no for its publication list (http://www.salutogenesis.hv.se/eng/ Publications.18.html)). A special treat for the visitor is a free copy of Antonovsky's, 1979 Health, Stress, and Coping!

Yet, despite the efforts of Bengt Lindström and Monica Eriksson, and many others, the need for a Handbook remains ... until now. Bengt and Monica have been central in the development of this volume, as a glance at the table of contents testifies. They were also key players in the birth of the idea for this book, especially Bengt, who is the founding head of the Global Working Group on Salutogenesis of the International Union for Health Promotion and Education (IUHPE). The website of the Working Group is certainly worth a visit, opening a door to salutogenesis and to the IUHPE, the premier global organization for health promotion (http://www.iuhpe.org/). By the time you read this, the leadership of the Global Working Group will have passed to the most capable hands of Georg Bauer, an Editor of this book, and a leading authority on salutogenesis. He will welcome your inquiry about the activities of the Working Group and your eagerness to become involved!

The paragraph above is not just free advertising for the IUHPE: this Handbook actually has its genesis as a project of the Global Working Group, a gathering place for the friends that are this book's editors. The Working Group has undertaken many projects listed at the IUHPE website, and the idea for this book arose at a 2012 project meeting of the Group, whose members are (in random order) Shifra Sagy, Geir Arild Espnes, Georg Bauer, Corey Keyes, Bjarne Bruun Jensen, Erio Ziglio, Monica Eriksson, Bengt Lindström, Maurice Mittelmark, Torill Bull, Antony Morgan, Mima Cattan, Lenneke Vaandrager, and Maria Koelen.

Having mentioned the IUHPE, it would be remiss not to mention the World Health Organization (WHO), and especially Ilona Kickbusch, who directed health promotion at WHO at the Regional Office in Copenhagen and later at the WHO global headquarters in Geneva. Under her leadership, health promotion at the WHO was explicitly salutogenic, with Ilona proclaiming that the salutogenic question-what 
are the origins of health-is the leading question for health promotion (Kickbusch, 1996).

The editorial team was aware from the first moment that as we are health promotion specialists, the book would have a health promotion flavor, yet we wished to reach to the interdisciplinary world of salutogenesis, not just to health promoters. Significant contributions to salutogenesis are in the literatures of nursing science, psychology, sociology, educational science, medicine, public health, health services research, and more. We have made the effort to write a book that is useful to this broad array of disciplines and specialties, and many chapter authors have affiliations reflecting the diversity.

We also have a passion, as part of our IUHPE genotype, to break the English language hegemony of the published literature (Perry \& Mittelmark, 2005). We have long been aware that important developments in salutogenesis are published in many languages other than English, and this Handbook gives us the opportunity to illuminate non-English literature in the Part edited by Bengt Lindström. The chapters in Bengt's Part are teasers of a sort, meant to excite interest and give readers entrée to heretofore "exotic" literatures. By having this access to the work of key researchers writing in other languages, readers are better enabled than before to crack the language barrier. However, many languages that might have been included are not, due only to practical limitations. I hope a second edition of the book will expand the offering.

Having just mentioned a particular Part of this book, I nevertheless resist the temptation to provide a section-bysection overview (just see the Table of Contents), but instead cherry-pick two chapters in this Part, to whet the appetite. The Chapter by Avishai Antonovsky and Shifra Sagy, Aaron Antonovsky: the scholar and the man behind salutogenesis, is a pearl worth the price the book all on its own (of course, the online edition is free!). Written by Israeli scholars with very close knowledge of Antonovsky-his son, and his wonderfully prolific Ph.D. student of many years ago - the chapter paints a portrait of Aaron Antonovsky that takes the subject of salutogenesis to an intimate level. Do you wish you had known Aaron? I never met the man to my great misfortune, but this chapter manages to make me almost think I had.

The chapter Aaron Antonovsky's development of salutogenesis, 1979-1994, by Hege Vinje, Eva Langeland and Torill Bull, is from the hands of particularly careful and critical scholars of Antonovsky's work. I know of no other extended synopsis of Antonovsky's work that is as accessible and informative, for the salutogenesis novice and for the expert alike. Not everyone has the time or access to all the books and papers needed to read Antonovsky as deeply and extensively as the authors of this chapter have done. This chapter is a trustworthy road map through the corpus of Antonovsky's life work on salutogenesis.
The meat of this Part-the chapters on the meanings of salutogenesis, on Antonovsky the man and the scholar, and on his body of salutogenesis work-set the stage for the myriad of viewpoints and scholastic interpretations offered in the rest of the book. Myriad of viewpoints and scholastic interpretations? Indeed, this is not a text, but rather a rich collection of diverse understandings from across generations, disciplines, and settings, and no effort has been made to harmonize the material from chapter to chapter. It has also been important to ensure that each chapter stands alone, as well as helping compose the book as a whole. In this day of e-books and open access, readers often select chapters and download them for reading without the "wrapping" of the entire book from which they are selected. This is why many of the chapter titles somewhat monotonously repeat the term "salutogenesis"- to ensure that literature searches using salutogenesis as a search term will have a reasonable likelihood of unearthing the chapters of this book.

A disclaimer: readers searching for a definitive and authoritative statement on the meaning and status of salutogenesis will not find it in this Handbook. Salutogenesis is still in scholastic infancy, it is forming, and it is developing. How the infant idea will develop as a mature idea is unknown. Here, we sketch the past, describe the present, and speculate on the future.

Closing, I extend my heartfelt appreciation to the editors and the authors, for their enthusiasm and cooperation. Scholarly books, as we all know, are the products of nights, weekends, and holidays. We write books for one another, for our academic friends. As a medieval monk supposedly lamented, writing is excessive drudgery. It crooks your back, it dims your sight, it twists your stomach and your sides. It is because we write for one-another that the aches are worth it.

And ... thank YOU, Aaron! We wrote this book for you, actually.

Open Access This chapter is distributed under the terms of the Creative Commons Attribution-Noncommercial 2.5 License (http:// creativecommons.org/licenses/by-nc/2.5/) which permits any noncommercial use, distribution, and reproduction in any medium, provided the original author(s) and source are credited.

The images or other third party material in this chapter are included in the work's Creative Commons license, unless indicated otherwise in the credit line; if such material is not included in the work's Creative Commons license and the respective action is not permitted by statutory regulation, users will need to obtain permission from the license holder to duplicate, adapt or reproduce the material.

\section{References}

Antonovsky, A. (1979). Health, stress and coping. San Francisco: Jossey-Bass.

Antonovsky, A. (1987). Unraveling the mystery of health-How people manage stress and stay well. San Francisco: Jossey-Bass.

Antonovsky, A. (1996). The salutogenic model as a theory to guide health promotion. Health Promotion International, 11(1), 11-18. 
Eriksson, M., \& Lindström, B. (2005). Validity of Antonovsky's sense of coherence scale: A systematic review. Journal of Epidemiology and Community Health, 59(6), 460-466.

Eriksson, M., \& Lindström, B. (2006). Antonovsky's sense of coherence scale and the relation with health: a systematic review. Journal of Epidemiology and Community Health, 60(5), 376-381.

Eriksson, M., \& Lindström, B. (2007). Antonovsky's sense of coherence scale and its relation with quality of life: a systematic review. Journal of Epidemiology and Community Health, 61(11), 938-944.

Eriksson, M., \& Lindström, B. (2008). A salutogenic interpretation of the Ottawa Charter. Health Promotion International, 23(2), 190-199.

Kickbusch, I. (1996). Tribute to Aaron Antonovsky-'What creates health'. Health Promotion International, 11, 5-6.
Lindström, B., \& Eriksson, M. (2005). Salutogenesis. Journal of Epidemiology and Community Health, 59(6), 440-442.

Lindström, B., \& Eriksson, M. (2006). Contextualizing salutogenesis and Antonovsky in public health development. Health Promotion International, 21(3), 238-244.

Lindström, B., \& Eriksson, M. (2010). The hitchhiker's guide to salutogenesis: Salutogenic pathways to health promotion. Helsinki: Folkhälsan Research Centre.

Perry, M. W., \& Mittelmark, M. B. (2005). The use of emerging technology to build health promotion capacity in regions with diversity in language and culture. Promotion \& Education, 13(3), 197-202. 